\title{
Antireflux Mucosectomy (ARMS): Innovative Endoscopic Treatment for Resistant Gastroesophageal Reflux (GERD)
}

\section{Nikolas Eleftheriadis ${ }^{1,2 *}$, Haruo Ikeda ${ }^{2}$, Manabu Onimaru' ${ }^{2}$, Ioanna Bravita $^{1}$, Eleni Eleftheriadou ${ }^{1}$, Grace Santi ${ }^{2}$ and Haruhiro Inoue ${ }^{2}$}

${ }^{1}$ Kyanous Stauros Euromedica, Thessaloniki, Greece

${ }^{2}$ Digestive Diseases Center, Showa University, Koto Toyosu Hospital, Japan

*Corresponding Author: Nikolas Eleftheriadis, Gastroenterologist, Kyanous

Stauros Euromedica, Greece.
Received: November 25, 2019

Published: January 23, 2020

(C) All rights are reserved by Nikolas

Eleftheriadis., et al.

DOI: 10.31080/ASGIS.2020.03.0113

Keywords: GERD; Antireflux Mucosectomy; Barrett'S Esophagus; Nissen Fundoplication

Gastroesophageal reflux disease (GERD) is defined as symptoms or mucosal damage produced by the abnormal reflux of gastric contents into the esophagus. Medical, endoscopic, and open/ laparoscopic surgical methods are used to treat GERD.

Over the last years a number of anti-reflux endoluminal procedures (suturing, injections, implants and radiofrequency energy application) have been developed for treating GERD, thus obviating the need for long-term proton pump inhibitors (PPI) and the potential morbidity of laparoscopic fundoplication. Although all these techniques were able to improve symptoms, the quality of life, PPI use and esophageal acid reduction were unremarkable. Moreover, some early endoscopic procedures have failed or proven unsafe, while no single endoscopic modality has been yet proved or accepted as the endoscopic therapy of choice for GERD.

Recently, antireflux mucosectomy (ARMS), based on natural scar formation after healing of the mucosal defect, has been proposed as minimally invasive, endoscopic treatment for PPI-resistant GERD, with no need of insertion or implantation of any artificial devices or prostheses into the lower esophagus, with exiting long-term results in pioneering centers. ARMS has been also successfully and effectively used in GERD patients with severe extraesophageal symptoms, such as respiratory symptoms, asthma, or chronic laryngitis, or bile reflux with low morbidity, hospitalization time and cost.

ARMS is performed in the endoscopy department, under conscious sedation, using the same, well-known, piecemeal endo- scopic mucosal resection with cup (EMR-C) technique, to complete a semi-circumferential mucosal ulcer at the GEJ no more than $2 / 3$ of the cardia circumference, according to initial description by (Inoue $\mathrm{H}$, et al. anti-reflux mucosectomy for gastroesophageal reflux disease in the absence of hiatus hernia: a pilot study. Ann Gastroenterol 2014;27:346-351.) (Figure 1A-C).

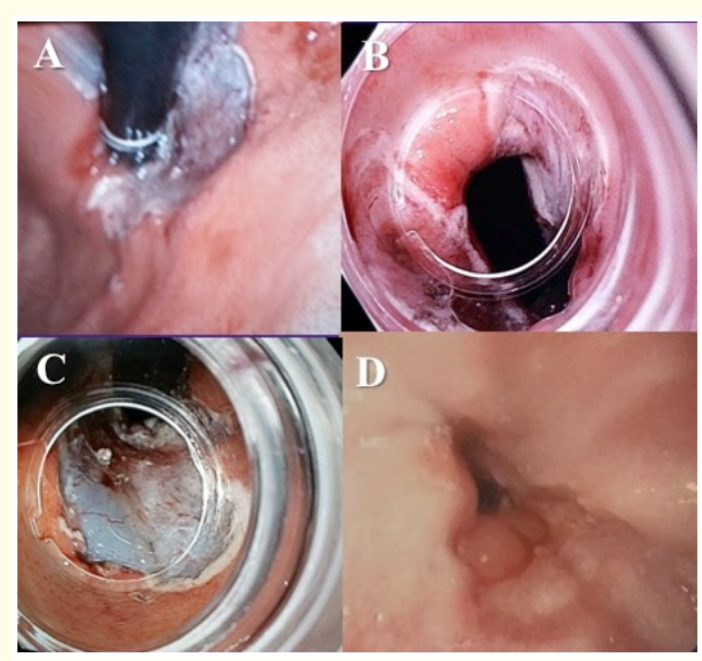

Figure 1: (A-D): EMR-C antireflux mucosectomy. 1A-C: GEJ and cardia semi-circumferential mucosectomy ulcer, including $1 \mathrm{~cm}$ above and $2 \mathrm{~cm}$ below the GEJ and with no more than $2 / 3$ of the cardia circumference are shown in retroversion $(1 \mathrm{~A}, 1 \mathrm{C})$ and forward view (1B). 1D: Excellent healing and closure of the GEJ without stenosis, one year after ARMS. 
EMR-C is the same technique used for endoscopic removal of Barrett's esophagus, a known premalignant GERD-related lesion. In GERD patients with co-existing Barrett's or micro-Barrett's esophagus, neither medications nor surgical or laparoscopic fundoplication can remove the Barrett's mucosa, while ARMS has a great advantage to treat GERD closing the GEJ with natural mode, while at the same time definitely remove the whole Barrett's esophagus, giving tissue for final histopathological examination (two-in-one). ARMS is the only endoscopic treatment for GERD, with this advantage.

As a result, after effective ARMS, no long-term endoscopic follow-up for Barrett's esophagus and no long-term PPI use is necessary, which has great impact on the quality of life, particularly in young patients, despite the risk-although low- of PPI-related sideeffects.

Unlike, painful, high-cost, surgical or even laparoscopic antireflux procedures, which, despite potential failures or complications, they also resulted in alterations to esophageal anatomy, producing technical difficulties in future endoluminal procedures, the minimal invasive ARMS procedure, performed like a simple gastroscopy, is painless and bloodless procedure, with no scar, low recovery time, low morbidity, immediate mobilization, no need for hospitalization and rapid return to normal. Moreover, treatment of failed or complicated GERD cases after surgical fundoplication is too difficult.

Among the different endoscopic therapies currently in use in specialized centers, ARMS is the most natural technique to close an open GEJ, easy, safe and with very low cost, because it is performed like a mucosectomy, it does not alter esophageal anatomy and with no need of insertion or implantation of any expensive and difficult to manipulate, with many risks, artificial devices or prostheses into the lower esophagus. Of course in cases with co-existing Barrett's esophagus, with this technique the whole Barrett's esophagus is removed before progressing to dysplasia and cancer, while at the same time the GEJ is naturally closed, definitely treating GERD.

According to initial promising experience, from the successful application of ARMS, although in pioneering centers, we consider ARMS as easy, safe and effective, endoscopic treatment for PPIresistant GERD, with low morbidity, hospitalization time and cost, with excellent outcome remained in long-term. However, long-term results from greater number of patients from different centers are necessary and awaited.

\section{Author Contributions}

Eleftheriadis N: Wrote the paper, performed research

Ikeda $\mathrm{H}$ : Performed research

Onimaru M: Performed research

Bravita I: Performed research

Eleftheriadou E: Performed research

Grace Santi: Performed research

Inoue H: Design research, performed research, analyzed the data.

\section{Conflict of Interest}

None

\section{Disclosure}

All authors disclosed no financial relationships relevant to this publication.

\section{Assets from publication with us}

- Prompt Acknowledgement after receiving the article

- Thorough Double blinded peer review

- Rapid Publication

- Issue of Publication Certificate

- High visibility of your Published work

Website: www.actascientific.com

Submit Article: www.actascientific.com/submission.php Email us: editor@actascientific.com

Contact us: +919182824667 